\title{
Comparison of short-term outcomes after carotid artery stenting according to different stent designs
}

\author{
Muslum Sahin, Göksel Açar, Birol Özkan, Gökhan Alıcı, Mehmet Vefik Yazıcıoglu, Mustafa Bulut, \\ Mehmet Emin Kalkan, Serdar Demir, Rezzan Deniz Acar, Bilal Boztosun
}

Kartal Kosuyolu High Speciality Education and Research Hospital, Istanbul, Turkey

Postep Kardiol Inter 2013; 9, 2 (32): 121-125 DOI: 10.5114/pwki.2013.35445

\begin{abstract}
Introduction: In the developed countries, stroke is the third most common cause of death. There are many data indicating that stents reduce the risk of embolism but there are few publications assessing whether different stent designs can influence the periprocedural complications.

Aim: To determine the effects of open- and closed-cell stent designs on 1-month results of carotid artery stenting (CAS).

Material and methods: The study group consisted of 290 consecutive patients (216 men and 74 women, mean age $66.6 \pm 8.7$ years). Neuroprotection with a distal protection device was used in all cases. The patients were divided into two groups: the opencell stent group $(n=144)$ and the closed-cell stent group $(n=138)$. Major adverse cardiac and cerebrovascular events (MACCE) described as myocardial infarction, stroke and death within 1 month were recorded and analysed subsequently. Periprocedural hypotension and transient cerebral ischaemia at 1 month after the CAS procedure were also assessed.

Results: We treated 290 carotid stenoses and stents were implanted in all patients. Fifteen patients (5.5\%) were treated by staged CAS due to bilateral carotid artery disease. The technical success rate was $97.2 \%$. There was no difference in the MACCE and transient cerebral ischaemia rate at 1 month between the two groups ( $p=0.44$ and $p=0.94$, respectively). The incidence of ischaemic stroke was lower in the closed-cell stent group $(2.77 \%$ vs. $0 \% ; p=0.04)$. The periprocedural rate of hypotension was higher in the closed-cell stent group ( $2.1 \%$ vs. $7.2 \% ; p=0.04)$.

Conclusions: Closed-cell stents are associated with a low rate of ischaemic stroke. We think that closed-cell stents may be preferred in patients at high risk of embolism.
\end{abstract}

Key words: carotid stenting, ischaemic stroke, stent design.

\section{Introduction}

In the developed countries, stroke is the third most common cause of death [1]. Extracranial carotid atherosclerosis with resulting atherothromboembolism may account for up to $30-40 \%$ of ischaemic strokes [2]. Thus, it leads to serious morbidity and mortality, and high cost to the health care system [3]. The mortality due to stroke has decreased in the last 50 years as a result of control of the risk factors, advances in pharmaceutical therapy, and development of effective interventions such as carotid endarterectomy (CEA) and carotid angioplasty and stenting (CAS) [3]. Despite numerous trials and clinical research, the optimal management of symptomatic and asymptomatic carotid disease remains controversial [4]. But in recent years CAS has replaced CEA in many patients [5]. With this technique, the stent fixes the atheromatous material to the vessel wall, and reduces the risk of embolism during dilatation. There are many data indicating that stents reduce the risk of embolism but there are few publications assessing whether different stent designs can influence the periprocedural complications $[6,7]$.

\section{Aim}

We sought to determine the effects of open- and closed-cell stent designs on 1-month outcomes after the CAS procedure.

\section{Material and methods}

Between January 2010 and December 2012, a total of 275 consecutive patients and 290 atherosclerotic carotid artery stenosis cases underwent CAS at the Kartal Kosuyolu High Speciality Education and Training Hospital. All

\section{Corresponding author:}

Muslum Sahin, Kartal Kosuyolu High Speciality Education and Research Hospital, 2 Denizer St Cevizli, Kartal, 34846 Istanbul, Turkey, tel.: +902165001500, e-mail: sahinm78@yahoo.com

Received: 20.02.2013, accepted: 22.04.2013. 
subjects gave written informed consent, and the study was approved by the ethics committee of the institution involved. Patients were divided into 2 groups according to stent designs: the open-cell stent (Protege ${ }^{\circledR}$ ) group and the closed-cell stent $\left(\right.$ Xact $\left.^{\circledR}\right)$ group. All stenoses were quantified angiographically according to the North American Symptomatic Carotid Endarterectomy Trial (NASCET) criteria [8]. The criteria to qualify for invasive treatment included the presence of asymptomatic stenosis of the carotid artery of $>70 \%$ or stenosis of $>50 \%$ in patients with a history of cerebrovascular events and/or critical stenosis of the contralateral carotid artery. Patients were excluded from the procedure only in case of total occlusion of the carotid artery or absolute contraindications for double anti-platelet therapy (active gastrointestinal bleeding, recent haemorrhagic stroke, allergy to aspirin), nonatherosclerotic carotid artery stenosis such as Takayasu's arteritis and fibromuscular dysplasia. Also patients with a history of incomplete data were excluded. In order to minimise the risk of thromboembolic complications, asymptomatic patients at least 2 days, symptomatic patients at least 5 days prior to the procedure received aspirin (300 mg/day) and clopidogrel (75 mg/day). In case of angiographic and ultrasonographic evidence of unstable atherosclerotic plaque containing clots, patients were pre-treated with anti-platelet agents and anticoagulants (aspirin, clopidogrel, low-molecular-weight heparin) for 2-4 weeks. A proximal balloon protection device (e.g., MOMA) was used or endarterectomy was performed in patients with persistent thrombus despite the treatment. In addition, patients still received their regular antihypertensive medications on the morning of the procedure. Sedatives were not applied prior to the procedure to facilitate accurate neurological assessment during angioplasty. The CAS procedures were all performed under local anaesthesia via femoral access. An $8 \mathrm{~F}$ introducer sheath was positioned and heparin (UFH $100 \mathrm{lU} / \mathrm{kg}$ of body weight) was administered to provide prolongation of ACT to 250-300 s, then continuous arterial pressure and electrocardiographic monitoring were performed during the procedure. Then an 8 F JR4 guiding catheter (Cordis) was placed proximally to the target lesion. A distal embolic protection with a vascular filter was used in all patients during CAS procedures. Following placement of the protection devices procedures were performed with pre-dilation (2-3 mm), stent deployment, and post-dilation (4.0$6.0 \mathrm{~mm}$ ). Pre-dilatation was performed only in case of critical stenosis (>95\%) or when severe calcifications were seen under fluoroscopy, to facilitate the stent's passage across the lesion. Self-expanding stents were implanted into the stenosed carotid arteries. If needed, the lesion was post-dilated to achieve a residual stenosis $\leq 30 \%$ after stent deployment. To prevent bradycardia and hypotension, 0.5-1.0 mg of atropine was routinely administered intravenously prior to balloon inflation. During the proce- dure, atropine (0.5-1.0 mg) was given again for patients who developed a $>20$ beats/min drop in their heart rate during balloon dilatation and stent deployment. In case of profound hypotension (systolic blood pressure $<80 \mathrm{~mm} \mathrm{Hg}$ ) infusion of inotropic agents (dopamine $5-15 \mu \mathrm{g} / \mathrm{kg} / \mathrm{min}$ ) and additional IV fluids were used. Before retrieval of the protection device, final biplane angiograms of the stented lesion as well as intracranial views were obtained. The procedure was considered successful when the stenotic segment of the carotid artery was effectively dilated (residual stenosis $<30 \%$ with adequate blood flow). After the procedure the anti-platelet therapy was continued (clopidogrel for the first 4-6 weeks in asymptomatic patients, 3 months in symptomatic patients and aspirin indefinitely). All patients were followed up in the intensive care unit for the first $3 \mathrm{~h}$ after the procedure. Also all the patients were repeatedly examined by physicians (including neurological examination) and all symptomatic patients were examined by board-certified neurologists. Post-procedural intracranial examination with magnetic resonance imaging (MRI) or computed tomography (CT) was performed if the neurological status of the patient changed. Meticulous blood pressure control was obligatory to maintain the systolic blood pressure between $100 \mathrm{~mm} \mathrm{Hg}$ and $130 \mathrm{~mm} \mathrm{Hg}$ or lower the blood pressure to $10 \%$ to $20 \%$ below baseline. All cardiovascular, neurological and local complications occurring during the index hospitalisation and after discharge, up to 30 days following the procedure, were recorded. Major adverse cardiac and cerebrovascular events (MACCE) described as myocardial infarctions (MI), stroke and death were also evaluated in this time period. Stroke was defined as a neurological deficit that persisted more than $24 \mathrm{~h}$. Transient cerebral ischaemia following the procedure was defined as occurrence of new or exacerbation of previously existing neurological symptoms with total recovery within $24 \mathrm{~h}$. The diagnosis of Q-wave MI was based on the presence of new $\mathrm{Q}$ waves on the ECG and an elevated creatine kinase at least 2 times the upper limit of the normal range with an elevated level of $M B$ isoenzyme. A non-Qwave MI had no new pathological Q-waves on ECG and a total creatine kinase of greater than two times the normal with an elevated MB isoenzyme. The ECG was performed persistently during the first $24 \mathrm{~h}$ and the remaining period of hospitalization in case of unexplained chest pain. Hypotension was defined as sustained postprocedural low blood pressure (<90 mm Hg, lasting > $30 \mathrm{~min}$ ).

\section{Statistical analysis}

The data were analysed using the Statistical Package for the Social Sciences (SPSS) software for Windows version 17.0 (SPSS Inc., Chicago, Illinois, USA). Parametric variables were reported as means and standard deviations, non-parametric as absolute numbers and percentages. Parametric variables were compared between groups using 
the independent sample $t$-test. Comparisons of the frequency of the non-parametric variables between subgroups were carried out using the $\chi^{2}$ test.

\section{Results}

In 290 patients, 290 CAS procedures were performed in our hospital (216 men and 74 women, mean age 66.6 \pm 8.7 years). Of these, $282(97.2 \%)$ procedures were successful. We did not succeed in 8 cases due to diffuse carotid stenosis, severe distortions in the internal carotid artery and anatomical abnormality of the aortic arch. Opencell stents were used in 144 cases (51\%), closed-cell stents in 138 cases (49\%). Fifteen patients (5.5\%) had a bilateral carotid artery disease. These patients were treated by staged CAS. Simultaneous bilateral carotid artery stenting was not performed in such patients. Table 1 shows the baseline characteristics, which, in general, were similar in both groups. Interventional and angiographic characteristics of the study population are summarized in Table 2 . The closed-cell stent group was associated with a greater degree of angiographic stenosis ( $86.8 \pm 10 \%$ vs. $83.6 \pm 11 \%$; $p=0.01)$. Also the pre-dilation ratio was higher in the closed-cell stent group (20.3\% vs. $11.1 \%$; $p=0.03)$. Contralateral stenosis $>50 \%$, contralateral occlusion ratio and rate of post-dilations were not significantly different between the two groups. The detailed data of all early events observed in both groups are presented in Table 3. There was no difference in the MACE rate between the two groups $(2.7 \%$ vs. $1.4 \% ; p=0.44)$. However, postprocedural strokes occurred in 4 patients and all strokes were in the open-cell stent group ( $2.7 \%$ vs. $0 \% ; p=0.04)$. On the other hand, two deaths occurred in the closed-cell stent group. One died as a consequence of periprocedural ischaemic stroke. The other patient underwent coronary stenting 15 days after the CAS procedure. This patient died as a result of contrast-induced nephropathy 2 days after the coronary stenting. The first patient was a 66-year-old man with multiple comorbid illnesses (hypertension, diabetes mellitus, hyperlipidaemia, current smoker, history of previous myocardial infarction and cerebrovascular accident). The second patient was a 78-year-old woman who had angina, coronary artery disease, hypertension, diabetes mellitus and hyperlipidaemia. There was no periprocedural myocardial infarction in both groups. Also, the transient cerebral ischaemia rate at 1 month was similar between the two groups $(p=0.94)$. The periprocedural rate of hypotension was higher in the closed-cell stent group than the open-cell stent group ( $7.2 \%$ vs. $2 \% ; p=0.04)$.

\section{Discussion}

In this study, we compared the periprocedural and onemonth outcomes of patients treated by carotid stents of different designs. There was no significant difference in the MACCE rates between the two groups. However, the ischaemic stroke rate was lower in the closed-cell stent
Table 1. Baseline clinical characteristics of patients

\begin{tabular}{lccc} 
Variables & $\begin{array}{c}\text { Open-cell } \\
\text { stent group } \\
(n=144)\end{array}$ & $\begin{array}{c}\text { Closed-cell } \\
\text { stent group } \\
(n=138)\end{array}$ & $\begin{array}{c}\text { Value } \\
\text { of } p\end{array}$ \\
\hline Age [years] & $66.6 \pm 9.2$ & $66.6 \pm 8.3$ & 0.99 \\
\hline Sex, men & $102(70.8 \%)$ & $110(79.7 \%)$ & 0.08 \\
\hline Hypertension & $120(83.3 \%)$ & $119(86.2 \%)$ & 0.49 \\
\hline Diabetes mellitus & $56(38.8 \%)$ & $42(30.4 \%)$ & 0.16 \\
\hline Hyperlipidaemia & $76(52.7 \%)$ & $77(55.7 \%)$ & 0.61 \\
\hline Current smokers & $45(31.2 \%)$ & $41(29.7 \%)$ & 0.81 \\
\hline Coronary artery disease & $107(74.3 \%)$ & $94(68.1 \%)$ & 0.25 \\
\hline Previous myocardial infarction & $26(18 \%)$ & $28(20.2 \%)$ & 0.58 \\
\hline $\begin{array}{l}\text { History of coronary artery } \\
\text { bypass grafting }\end{array}$ & $37(25.6 \%)$ & $23(16.6 \%)$ & 0.06 \\
\hline $\begin{array}{l}\text { Previous coronary artery } \\
\text { intervention }\end{array}$ & $42(29.1 \%)$ & $40(28.9 \%)$ & 0.95 \\
\hline $\begin{array}{l}\text { Peripheral arterial disease } \\
\text { Rate of symptomatic patients }\end{array}$ & $17(11.8 \%)$ & $22(15.9 \%)$ & 0.25 \\
\hline $\begin{array}{l}\text { Hospitalization time } \\
\text { Variables are expressed as mean } \pm \text { standard deviation or frequencies } \\
\text { (percentages) }\end{array}$ & $72(52.1 \%)$ & 0.20 \\
\hline
\end{tabular}

Table 2. Interventional and angiographic characteristics of the study population

\begin{tabular}{lccc} 
Variable & $\begin{array}{c}\text { Open-cell } \\
\text { stent group } \\
(n=144)\end{array}$ & $\begin{array}{c}\text { Closed-cell } \\
\text { stent group } \\
(n=138)\end{array}$ & $\begin{array}{c}\text { Value } \\
\text { of } p\end{array}$ \\
\hline Lesion located in LICA/RICA & $\begin{array}{c}80(55 \%) / \\
64(44 \%)\end{array}$ & $\begin{array}{c}73(52 \%) / \\
65(47 \%)\end{array}$ & 0.65 \\
\hline Stenosis at baseline & $83.6 \pm 11.6$ & $86.8 \pm 10.8$ & 0.01 \\
\hline Contralateral stenosis $>50 \%$ & $19(13.1 \%)$ & $33(23.9 \%)$ & 0.06 \\
\hline Contralateral occlusion & $7(4.8 \%)$ & $12(8.6 \%)$ & 0.39 \\
\hline Rate of pre-dilations & $16(11.1 \%)$ & $28(20.2 \%)$ & 0.03 \\
\hline Rate of post-dilations & $128(88.8 \%)$ & $127(92.0 \%)$ & 0.37 \\
\hline Mean stent length [mm] & $38.0 \pm 7.4$ & $37.1 \pm 7.2$ & 0.34
\end{tabular}

Variables are expressed as mean \pm standard deviation or frequencies (percentages). LICA - left internal carotid artery, RICA - right internal carotid artery

Table 3. Periprocedural and 1-month outcomes of patients

\begin{tabular}{lccc} 
Type of complication & $\begin{array}{c}\text { Open-cell } \\
\text { stent group } \\
(n=144)\end{array}$ & $\begin{array}{c}\text { Closed-cell } \\
\text { stent group } \\
(n=138)\end{array}$ & $\begin{array}{c}\text { Value } \\
\text { of } p\end{array}$ \\
\hline Death & $0(0 \%)$ & $2(1.4 \%)$ & 0.14 \\
\hline Stroke & $4(2.7 \%)$ & $0(0 \%)$ & 0.04 \\
\hline Myocardial infarction & 0 & 0 & NS \\
\hline MACCE & $4(2.7 \%)$ & $2(1.4 \%)$ & 0.44 \\
\hline Transient cerebral ischaemia & $5(3.4 \%)$ & $5(3.6 \%)$ & 0.94 \\
\hline Hypotension & $3(2.0 \%)$ & $10(7.2 \%)$ & 0.04
\end{tabular}

Variables are expressed as frequencies (percentages). MACCE - major adverse cardiac and cerebrovascular events, NS - non-significant 
group than the open-cell stent group, while the rate of hypotension was higher with closed-cell stents.

Extracranial carotid atherosclerosis is a major cause of ischaemic stroke [9]. Multiple treatments have been shown to be efficacious in treating carotid disease. Carotid endarterectomy has been shown to be effective in significantly reducing the risk of recurrent stroke emanating from that pathological nidus [10]. On the other hand, CAS as a novel method for carotid revascularization in the past 10 years has been widely used in patients with significant carotid artery stenosis as an alternative to CEA [11].

There are many studies comparing CAS and CEA. The analysis of pooled data from EVA-3S, SPACE and CREST demonstrated higher periprocedural risk of stroke and death with CAS compared to endarterectomy [12]. The EVA$3 \mathrm{~S}$ study suggested that the 30-day incidence of any stroke or death was higher in the stenting group [13]. In the CREST trial, there was no significant difference in the rates of the primary end point (stroke, death and MI) between CAS and CEA [14]. But in the same study the stroke rate was higher in the CAS group, and the MI rate was higher in the CEA group (stroke $4.1 \%$ vs. $2.3 \%, p<0.012$; and MI $1.1 \%$ vs. $2.3 \%$, $p<0.032$ ).

A major limitation of CAS is the potential for embolic stroke caused by plaque dislodgement of atheromatous material during the procedure [15]. This risk can be present at any stage of the endovascular treatment [16]. Embolic signals have been detected during wire crossing, advancing the distal protection device, balloon predilatation, stent deployment and post-stent balloon dilatation by using magnetic resonance imaging and transcranial Doppler monitoring [17-19]. Stent design may influence the risk of distal embolization $[6,7,20]$. However, there are limited data on this issue. The results of these few studies are conflicting. Bosiers et al. [20] analysed 3,179 CAS procedures. According to that analysis, postprocedural adverse events were more frequent in open-cell stents compared to closed-cell stents. However, in the studies by Mukherjee et al. [21] and Maleux et al. [22], adverse events were not different between open-cell stents and closed-cell stents.

In our study, we found no significant difference in the MACCE rates, whereas the stroke rate was significantly higher in the open-cell stent group. We believe that the high stroke rate in the open-cell stent group is related to stent design. The potential advantage of closed-cell stents with a smaller free cell area and hence a greater percentage of wall coverage is that the stent may contain the fractured plaque after angioplasty, resulting in a lower number of postprocedural events [3].

Tadros et al. [23] investigated the effects of open- and closed-cell stents on the size and number of embolic particles generated during the CAS procedure. They found that open-cell stents are associated with a larger mean particle size compared to closed-cell stents. In our study, the degree of baseline angiographic stenosis and the ratio of pre-dilata- tion were higher in the closed-cell stent group compared to the open-cell stent group. Despite these higher risk profiles for stroke, the stroke rate was lower in the closed-cell stent group. Thus, our results in agreement with the previous study [23] suggested that the closed-cell stents are sufficient to cover the plaque and to prevent postprocedural large plaque embolization through the stent struts. Also, inhibition of platelet aggregation may be another mechanism. Gurbel et al. [24] analysed platelet activation following closed-cell or open-cell coronary stent implantation in an ex vivo model. They found decreased platelet aggregation and reduced expression of multiple surface markers in the closed-cell stent group. They hypothesized that this finding may be related to less intimal prolapse and a smoother luminal contour after implantation of a closed-cell stent.

Carotid sinus reaction including bradycardia, asystole, and hypotension is one of the most common complications of internal carotid artery angioplasty. It can occur during or after CAS due to over-stretching of the carotid sinus baroreceptors by the balloon or the stent [25]. In our study, the rate of hypotension was higher in the closed-cell stent than the open-cell stent group. This difference may be associated with stent design and the radial force of stents. Generally, closed-cell stents' outward radial force is higher. Conversely, open-cell stents' outward radial force is lower and more flexible. Therefore, closed-cell stents apply more pressure on the carotid sinus and consequently may lead to hypotension. Also, our patients in the closed-cell stent group had a higher angiographic stenosis rate, requiring higher pre- and post-dilatation pressure to achieve the appropriate vessel size. Therefore, aggressive pre- and postdilatation in those patients could account for the higher rate of hypotension.

Our study has some limitations. First, this was a retrospective study, and it has all the limitations inherent to this type of study. Second, we did not use diffusion-weighed $M R I$ imaging. And we evaluated only the periprocedural and one-month clinical results after CAS. Therefore, further research is needed to assess the long-term effects of openand closed-cell stent designs on the results of CAS.

\section{Conclusions}

Our results showed that carotid stent design may influence procedural outcomes; closed-cell stents reduce the rate of ischaemic stroke by preventing plaque protrusion. We think that closed-cell stents may be preferred in patients with a high thrombus burden.

\section{References}

1. deWeerd M, Greving JP, Hedblad B, et al. Prevalence of asymptomatic carotid artery stenosis in the general population: an individual participant data meta-analysis. Stroke 2010; 41: 1294-1297.

2. Sudlow CL, Warlow CP. Comparing stroke incidence world wide: what makes studies comparable? Stroke 1996; 27: 550-558.

3. Hussain HG, Aparajita R, Khan SZ, et al. Closed-cell stents present with higher velocities on duplex ultrasound compared with open- 
cell stents after carotid intervention: short- and mid-term results. Ann Vasc Surg 2011; 25: 55-63.

4. Jansen O, Fiehler J, Hartmann M, et al. Protection or non protection in carotid stent angioplasty: the influence of interventional techniques on outcome data from the SPACE Trial. Stroke 2009; 40: 841-846.

5. Levy E, Yakubovitch D, Rudis E, et al. The role of combined carotid endarterectomy and coronary artery bypass grafting in the era of carotid stenting in view of long-term results. Interact Cardiovasc Thorac Surg 2012; 15: 984-988.

6. Bosiers M, de Donato G, Deloose K, et al. Does free cell area influence the outcome in carotid artery stenting? Eur J Vasc Endovasc Surg 2007; 33: 135-141.

7. Schillinger M, Gschwendtner M, Reimers B, et al. Does carotid stent cell design matter? Stroke 2008; 39: 905-909.

8. U-King-Im JM, Trivedi RA, Cross JJ, et al. Measuring carotid stenosis on contrast-enhanced magnetic resonance angiography: diagnostic performance and reproducibility of 3 different methods. Stroke 2004; 35: 2083-2088.

9. Petty GW, Brown RD Jr, Whisnant JP, et al. Ischemic stroke subtypes: a population-based study of incidence and risk factors. Stroke 1999; 30: 2513-2516.

10. Taylor DW, Barnett HJM. Beneficial effect of carotid endarterectomy in symptomatic patients with high-grade carotid stenosis. N Engl J Med 1991; 325: 445-453.

11. Wholey MH, Al-Mubarak N, Wholey MH. Updated review of the global carotid artery stent registry. Catheter Cardiovasc Interv 2003; 60: 259-266.

12. Amarenco P, Labreuche J, Mazighi M. Lessons from carotid endarterectomy and stenting trials. Lancet 2010; 376: 1028-1031.

13. Mas JL, Chatellier G, Beyssen B, et al. Endarterectomy versus stenting in patients with symptomatic severe carotid stenosis. N Engl J Med 2006; 355: 1660-1671.

14. Hobson RW, Howard VJ, Roubin GS, et al. Carotid artery stenting is associated with increased complications in octogenarians: $30-$ day stroke and death rates in the CREST lead-in phase. J Vasc Surg 2004; 40: 1106-1111.

15. Baldi S, Zander T, Rabellino M, et al. Carotid artery stenting without angioplasty and cerebral protection: a single-center experience with up to 7 years follow-up. Am J Neuroradiol 2011; 32: 759-763.

16. Aydiner O, Boztosun B, Sirvanci M, et al. Early and late outcomes of carotid artery stenting. Anadolu Kardiyol Derg 2007; 7: 152-157.

17. Jaeger HJ, Mathias KD, Drescher R, et al. Diffusion-weighted MR imaging after angioplasty plus stenting of arteries supplying the brain. Am J Neuroradiol 2001; 22: 1251-1259.

18. Gerraty RP, Bowser DN, Infeld B, et al. Microemboli during carotid angiography: association with stroke risk factors or subsequent magnetic resonance imaging changes. Stroke 1996; 27: 1543-1547.

19. Van Heesewijk HP, Vos JA, Louwerse ES, et al. New brain lesions after carotid angioplasty and stent placement. Radiology 2002; 224: 361-365.

20. Bosiers M, de Donato G, Deloose K, et al. Does free cell area influence the outcome in carotid artery stenting? Eur J Vasc Endovasc Surg 2007; 33: 135-141.

21. Mukherjee D, Kalahasti V, Roffi M, et al. Self-expanding stents for carotid interventions: comparison of nitinol versus stainless-steel stents. J Invasive Cardiol 2001; 13: 732-735.

22. Maleux G, Marrannes J, Heye S, et al. Outcome of carotid artery stenting at 2 years follow-up: comparison of nitinol open cell versus stainless steel closed cell stent design. J Cardiovasc Surg 2009; 50: 669-675.
23. Tadros RO, Spyris CT, Vouyouka AG, et al. Comparing the embolic potential of open and closed cell stents during carotid angioplasty and stenting. J Vasc Surg 2012; 56: 89-95.

24. Gurbel PA, Callahan KP, Malinin Al, et al. Could stent design affect platelet activation? Results of the platelet activation in stenting (PAST) study. J Invasive Cardiol 2002; 14: 584-589.

25. Nii K, Tsutsumi M, Aikawa $\mathrm{H}$, et al. Incidence of hemodynamic depression after carotid artery stenting using different selfexpandable stent types. Neurol Med Chir 2011; 51: 556-560. 